\title{
Autonomous photovoltaic observatory station integrated with UAV - a case study
}

\author{
Slawomir Gulkowski ${ }^{1, *}$, Agnieszka Skomorowska ${ }^{2}$ \\ ${ }^{1}$ Institute of Renewable Energy Engineering, Faculty of Environmental Engineering, Lublin University \\ of Technology, 40B Nadbystrzycka Str., 20-618 Lublin, Poland \\ ${ }^{2}$ Student Research Group "Grupa Ogniwo", Faculty of Environmental Engineering, Lublin University \\ of Technology, 40B Nadbystrzycka Str., 20-618 Lublin, Poland
}

\begin{abstract}
Over the past few decades the World has experienced a revolution in Energy production from solar technology, mostly from photovoltaics. On the other hand, an increasing number of unmanned aerial vehicle (UAV) applications are also noticed. Combining photovoltaics and UAVs reveals many opportunities for researchers and renewable energy industry. Responding to the challenge of large area observations at remote locations, the conception of an autonomous photovoltaic station integrated with UAV has been proposed. The essential advantage of the station is its energetic autonomy. The station is movable and can be installed in various locations all over the World. It can be implemented for a wide range of applications, i.e. examining hydroelectric, solar or wind power stations. The simulation results of energy production from PV system mounted on the station have been shown in this work. Several issues were taken into account for the calculations: tilt and azimuth of PV modules, irradiation at case study location and energy demand of the station's equipment. The energy usage of five and eight hours daily of UAV flights was estimated. Energy balance was calculated.
\end{abstract}

\section{Introduction}

According to Directive 2009/28/EC of the European Parliament and Council on the promotion of the use of energy from renewable sources $20 \%$ of the final energy consumption should derive from renewable energy resources by the year of 2020 . However, the goal is different for each EU country and depends on gross domestic product. For example the 2020 target in Germany or the Czech Republic is equal to $18 \%$ and $13 \%$ respectively. In Poland the goal is $15 \%$ [1]. For this reason, an increase of the global investments in renewable energy installations could be observed in the last few years. The total installed renewable power capacity in Poland in 2016 was $8.5 \mathrm{GW}$ with the $6 \mathrm{GW}$ of wind power installations and by $1 \mathrm{GW}$ of hydro and biomass power plants [2]. Availability of renewable energies depends on the culture of individual communities and distribution of the natural resources which depends on geographical locations [3-4]. Solar energy is available in most areas of our planet. About $3.8 \cdot 10^{24} \mathrm{~J}$ of solar energy can be obtained on Earth's surface which is 6000 times greater than the world consumption [5].

*Corresponding author: s.gulkowski@pollub.pl 
Photovoltaic systems based on direct conversion of sunlight into electricity seems to be a very promising solution in the area of energy production. They are non-polluting and require very little maintenance. The overall cost is the initial cost of the investment. They do not create greenhouse gases and wastes that must be stored [6]. Another advantage of utilizing PV systems is their suitability for off grid applications [7-8].

Stand alone photovoltaic (SAPV) systems are not connected to the public grid and use batteries to storage energy produced by the photovoltaic modules. These kinds of installations can be cost effective in remote areas [9] and in some locations as rooftop systems. Benefits of using SAPV were pointed out in work of [10]. Reduction of the peak load and the use of electricity in the place of production leads to the lower power losses that occur during transmission and distribution energy to the grid. What is more, there are still many places in the world with no access to the electricity where PV system seems to be a convenient choice. However, due to the uncertain nature of this resource, it can be used as the back-up for traditional energy resource [11]. In Tanzania for example, about $24 \%$ of the population has access to the electricity and $93 \%$ of rural households suffer from lack of electricity. Many students are forced to study at night with the use of poor light from kerosene lamps. For these areas off grid systems are huge promises to have a better life. For this reason in the work of [12] a proposition of small SAPV were shown.

Refs. [10] proposes the use of standalone PV system for a hostel building. Design of $110 \mathrm{kWp}$ PV installation with the energy prediction was described in details. Another detailed analysis of hybrid renewable energy sources (HRES) with the use of HOMER application points the $6 \mathrm{kWp} \mathrm{SAPV}$ installation as the most effective from an energetic, economic and ecological point of view for a health clinic placed in a rural area of Iraq [13]. A literature review of [14] indicates many case studies of design and planning off grid renewable energy systems for households, health centres, remote areas and villages. An interesting comparison of renewable energy system usage for small sized tourists accommodation in remote areas of Australia was presented in [15]. The characterisation of location, energy consumption, and a low toleration for failure were included in the analysis. Costs and payback time for different combination of HRES were examined.

The objective of this work is to propose a case study of standalone autonomous system that can be used as a observatory station by researchers or workers in all remote areas with the access to the sunlight, i.e. national parks, watery fields, mountains. The station is integrated with unmanned aerial vehicle (UAV) for the observations. Although a wide range of applications of UAV can be distinguished: examining windmills, border control, PV system exploration, cleaning of solar panels, we decided to focus on large PV solar power plants thermography analysis. As the case study, Solar Park Meuro located in eastern Germany with 636000 PV modules and the total power capacity of $166 \mathrm{MWp}$ was chosen. Solar Park Meuro covers 200 hectares of area which is a major challenge for thermography analysis. Calculation of energy production was carried out on the basis of modules installed on the station and solar irradiance conditions in chosen location. Detailed energy balance analysis was shown for different amount of UAV working hours.

This paper is organized as follows. Section 2 describes the exterior and interior design of the observatory station with the PV system mounted on the walls of the container. A drone as well as an infrared camera proposed for the case study of thermography analysis are also described. At the end of this section, estimation of energy usage by UAV and other equipment of the observatory station is presented. The results of solar irradiation and energy production of the PV system at the case study location together with energy usage by UAV are presented in Section 3. Conclusions are given in Section 4. 


\section{Materials and methods}

\subsection{Design of the station}

The observatory station is based on the container with a photovoltaic installation mounted on three walls to fulfill the electricity demand for the station and integrated systems. A container with the size of $6.1 \times 2.4 \times 2.6 \mathrm{~m}$ is composed of high quality and durable materials. Construction of the station assumes the possibility of easy transport. The interior provides convenient working conditions: LED lightning, air conditioning, heating, an office desk for computer, and a board for UAV. Fig. 1 illustrates the interior of the container.

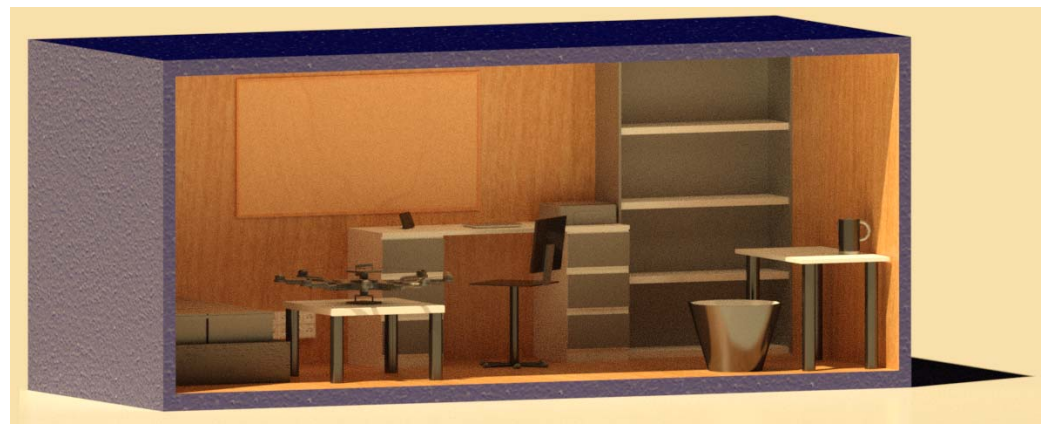

Fig. 1. Visualisation of the stations' interior.

Photovoltaic installations with a battery bank guarantee total autonomy and energy independence. It allows carrying out the observations even in the area without access to the public grid. The best example is monitoring of national parks. Furthermore, with its own electricity the station can be installed elsewhere under the condition of exposure to sunlight. PV installation consists of 18 monocrystalline solar modules with the energy conversion efficiency of $21.1 \%$. The total installed power capacity is $6.57 \mathrm{kWp}$. Three groups of modules were planned on the roof, the back wall, and on additional movable wall which allows optimal tilt settings. 3D visualisation of the station with PV system is pictured in Fig. 2.

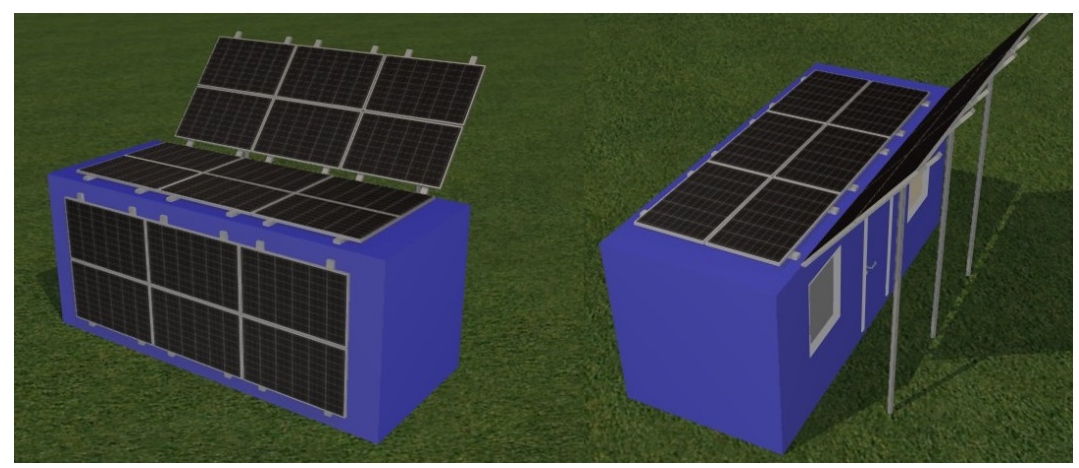

Fig. 2. Visualisation of the exterior view of the station.

According to energy load requirements, presented in section 2.3, storage batteries were planned to maintain the functionality of the station. The sizing method of the battery storage was based on the concept of energy consumption. It leads to decrease the total installation costs and thus force the operators to use the energy more efficiently. Battery 
size calculations were carried out for the maximum depth of discharge equal to 0.7 , inverter efficiency equal to $97 \%$ and 3 autonomous days for which energy for the station comes solely from the batteries. Capacity of the system is $1000 \mathrm{Ah}(24 \mathrm{~V})$. The primary device that has to be used to prevent damage of the batteries is the charge controller. Its function is to maintain the battery at the highest possible state of being charged and to protect them from deep discharge and overcharge regardless of the system design and seasonal changes in the load profile. Three solar charge controllers (140 A, $24 \mathrm{~V}$ ) were proposed separately. Voltage of the system on DC side is compatible to output of chosen batteries voltage, i.e. $24 \mathrm{~V}$, and operate according to voltage range of the charge controllers. In order to fulfill electricity for all equipment of the station, the inverter was planned to convert the generated DC voltage into AC voltage of required value $(230 \mathrm{~V}, 50 \mathrm{~Hz})$. Data logger and necessary protections were included inside the unit. The chosen inverter has the following parameters: input power: $2 \mathrm{~kW}$, efficiency: $97 \%$, input DC voltage: $24 \mathrm{~V}$.

\subsection{Unmanned aerial vehicle}

The major device of the proposed observatory station is the unmanned aerial vehicle (UAV). For the purposes of large PV systems examination DJI Matrice 210 showed in Fig. 3 was suggested. A UAV of this type was chosen due to the high performance in parallel with relatively small dimensions $(716 \times 220 \times 236 \mathrm{~mm})$ and weight $(3.8 \mathrm{~kg})$. Advanced technologies allow it to fly stably during a gust of wind. Numerous detectors can identify and help to by-pass the obstacles. The drone is powered by two batteries with a capacity that allows it to fly for half an hour. However, with the use of a charging hub there is possibility to change the batteries in order to keep continuity of inspection. The UAV is delivered with the data analysis software. The implemented light bright system allows the live transmission and flight range of up to $4 \mathrm{~km}$. The span of the drone depends on the play load that can be up to $2 \mathrm{~kg}$ lifting capacity.

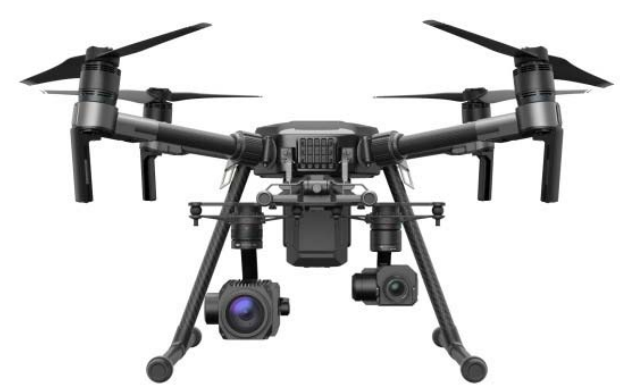

Fig. 3. UAV of DJI Matrice 210 type proposed for IR thermography examination [16].

\subsection{Infrared thermography camera}

DJI Matrice can interoperate with many devices. For the purposes of the presented case study, the relevant tool is DJI Zenmuse XT infrared camera, which is responsible for thermal analysis. Thermovision provides the possibility of solar power plant inspection. It is compatible with the UAV of Matrice 201 type and uses its energy for operation. During the examination overheated areas of the modules (hot-spots) that negatively affect the efficiency can be detected. The quality of image is assured by spot metering with the resolution of $640 \times 512$ pixels. The gimbal of the camera is mounted at the bottom of the $\mathrm{UAV}$ and gives an opportunity to manipulate the rotation in $360^{\circ}$. 


\subsection{Energy consumption}

Station load profile analysis presented in Table 1 shows that daily demand for power and energy are $1.3 \mathrm{~kW}$ and $6.4 \mathrm{kWh}$ for the station and $3.5 \mathrm{kWh}$ for 10 flights of the UAV ( 5 working hours). In terms of 16 flights ( 8 hours of work) these values increase to $10 \mathrm{kWh}$ of energy for the station and about $5.6 \mathrm{kWh}$ for the drone. Calculations consist of minimum energy demand. Including energy losses due to efficiency of the batteries (0.9), the required energy for the daily charge is found to be about $11 \mathrm{kWh}$ and $18 \mathrm{kWh}$ for considered periods. It should be emphasized that all facilities of the station (lightning, air condition system, computer, measurement systems) are planned to work for the same time period as the UAV. The time spent using the charging hub is connected to the number of UAV flights. The single route of drone flight with an infrared camera requires two batteries which have to be charged for 3 hours. The storage battery of control gear requires $2.5 \mathrm{~h}$ of charging. The capacity of navigate system battery enables from 2.5 to 4 hours of application.

Table 1. Energy load of the station.

\begin{tabular}{lccccc}
\hline \multicolumn{1}{c}{ Indyvidual load } & $\begin{array}{c}\text { Power } \\
{[\mathbf{W}]}\end{array}$ & $\begin{array}{c}\text { Time } \\
{[\mathbf{h} / \mathbf{d a y}]}\end{array}$ & $\begin{array}{c}\text { Energy load } \\
{[\mathbf{W h} / \text { day }]}\end{array}$ & $\begin{array}{c}\mathbf{x} \text { 7 } \\
{[\mathbf{k W h} / \mathbf{w e e k}]}\end{array}$ & $\begin{array}{c}\mathbf{x ~ 3 1} \\
{[\mathbf{k W h} / \mathbf{m o n t h}]}\end{array}$ \\
\hline 1 flight of UAV $(0.5 \mathrm{~h})$ & 117 & 3 & 351 & 2.46 & 10.88 \\
\hline Controller charging & 117 & 5 & 585 & 4.10 & 18.14 \\
Air conditioner & 970 & 5 & 4850 & 33.95 & 150.35 \\
Laptop & 50 & 5 & 250 & 1.75 & 7.75 \\
Anemometer & 0.6 & 24 & 14.4 & 0.10 & 0.45 \\
Pyranometer & 1 & 24 & 24 & 0.17 & 0.74 \\
Lightning & 120 & 5 & 600 & 4.20 & 18.60 \\
\hline & & & Total daily & Total weekly & Total monthly \\
& & & 6323.4 & 44.26 & 196.03 \\
\hline
\end{tabular}

\section{Results}

The solar resource data used for the analysed case study of Solarpark Meuro at the location of $51^{\circ} 34^{\prime} \mathrm{N}$ latitude and $13^{\circ} 59^{\prime} \mathrm{E}$ longitude were calculated with the use of an online solar photovoltaic energy calculator (PVGIS) [17]. Daily solar irradiation on a horizontal and two tilted planes of the station $\left(90^{\circ}, 24^{\circ}\right)$ is shown by the bar graph in Fig. 4. Total average irradiation calculated for each month is shown on the line graph. As it can be seen, irradiation varies from a minimum value of $0.7 \mathrm{kWh} / \mathrm{m}^{2}$ in December to maximum value of $4.7 \mathrm{kWh} / \mathrm{m}^{2}$ in June. Apart from the solar irradiation the energy production depends also on the temperature of the module. The calculated energy performance includes the temperature correction factor estimated on the basis of the Postdam reference station [18]. The parameter varies between 0.9 and 1.0 from March to October and increases up to 1.05 for low temperature days from November to February. Daily average production of energy from the stations' PV system is presented in Fig. 5. Energy demand including given working conditions for each month of the year was indicated with a dotted line. The lowest level of energy production was noticed in December and January with the daily values of $4.4 \mathrm{kWh}$ and $5.1 \mathrm{kWh}$ respectively. 


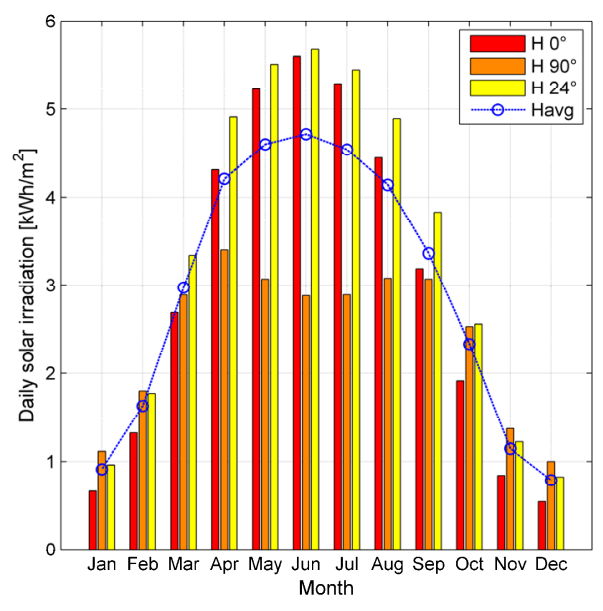

Fig. 4. Daily solar irradiation at location of Meuro in $\operatorname{Germany}\left(\varphi=51^{\circ}\right)$.

From March to October the amount of energy produced by photovoltaic system of the station exceeds the load demand for the case of 5 working hours. In terms of 8 working hours of the station this number decreases to five months, i.e. from April to August (see Fig. 6).

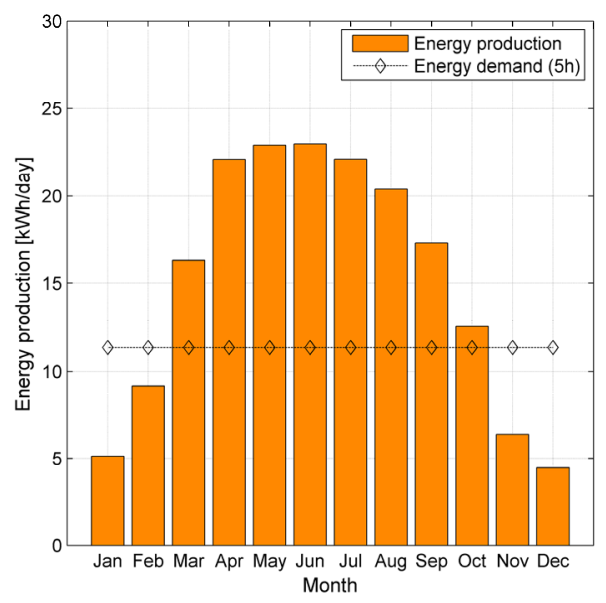

Fig. 5. Energy production and demand of the station with assumption of five UAV working hours.

Fig. 6 presents energy balance with the assumption of $5 \mathrm{~h}$ and $8 \mathrm{~h}$ of UAV flight. Five hours of flight between $10 \mathrm{a} . \mathrm{m}$ and 3 p.m. during sunny days assures high enough irradiance level for the IR thermography examination $\left(900-1,000 \mathrm{~W} / \mathrm{m}^{2}\right)$. As it was shown, most of the months allow continuous drone flights during the day. Besides, much more energy produced by the PV system of the station allows keeping the battery fully charged on one hand, and on the other hand charging more electrical devices that can be used inside or outside the station. For the four winter months (November-February) the amount of energy produced by the PV system is insufficient to keep the continuous inspection carried out by the UAV for five hours. However, in this case study of the station application for IR thermography inspections the location of $51^{\circ}$ is characterised by only a few sunny days with irradiance above $900 \mathrm{~W} / \mathrm{m}^{2}$ [19-22]. Thus, there is no reason to increase system 
installation size to obtain more energy in winter months. In terms of eight working hours of the station the amount of energy allows keeping the inspections continuously during five months from April to August. For the rest of the months some limitations of drone flights have to be introduced because of the possible lack of the energy from the PV system.

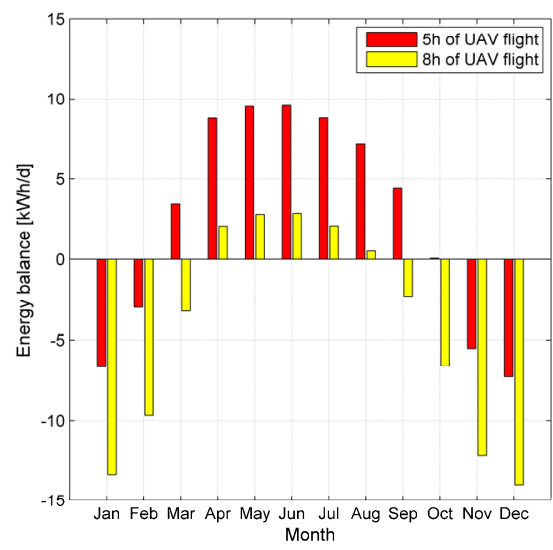

Fig. 6. Energy balance for $5 \mathrm{~h}$ and $8 \mathrm{~h}$ of station work including UAV continuous flights.

\section{Conclusions}

An increasing number of large PV power plants forces the investors to look for the effective and fast methods of PV systems examination in terms of many different faults that can affect the efficiency of the modules (hot spots). The proposed autonomous station integrated with UAV equipped with IR thermography camera seems to be a good solution for these purposes because of easy transportation and energy independence. The proposed station can be installed elsewhere on the condition of access to direct sunlight. The equipment in the interior powered by PV installation provides convenient working conditions in hot, sunny days of the IR thermography examination. The proposed PV system can deliver energy for equipment of the station and for UAV flights. What is more, it allows keeping the battery charged for most days of the year, excluding winter months for which the irradiance level is too low for IR thermography analysis in this climate condition. Energy balance showed that for at least five months the proposed station can deliver comfortable conditions for five as well as eight working hours including continuous drone flights. In the future work this conception is going to be developed as a hybrid renewable energy system consisting of a PV system and a wind turbine for better energy balance in summer as well as in winter months.

\section{References}

1. Directive 2009/28/EC of the European Parliament and of the Council of 23 April 2009 on the promotion of the use of energy from renewable sources and amending and subsequently repealing Directives 2001/77/EC and 2003/30/EC

2. Report Photovoltaic market in Poland, Institute for Renewable Energy, Warsaw, (2017)

3. J. Mohtasham. Enrgy Proced. 74, 1289-1297 (2015)

4. J. M. Olchowik, K. Cieslak, S. Gulkowski, J. Mucha, M. Sordyl, K. Zabielski, D. Szymczuk, A. Zdyb, Photovoltaic Specialists Conference (PVSC), 35th IEEE, 002397-002399 (2010) 
5. A. K. Shukla, K. Sudhakar, P. Baredar, Energy Reports 2, 82-88 (2016)

6. M. Dale, Applied Sciences 3, 325-337 (2013)

7. S. Rehman, I. El-Amin, Energy 46, 451-458 (2012)

8. W. Grzesiak, P. Mackow, T. Maj, A. Polak, E. Klugmann-Radziemska, S. Zawora, K. Drabczyk, S. Gulkowski, P. Grzesiak, Sol. Energy 132, 442-452 (2016)

9. N. Dalilah Nordin, H. Abdul Rahman, Renew. Ener. 89, 706-715 (2016)

10. A. K. Shukla, K. Sudhakar, P. Baredar, Sol. Energy 136, 437-449 (2016)

11. S. Bahramara, M. Parsa Moghaddam, M.R.Haghifam, Renew. Sust. Energ. Rev. 62, 609-620 (2016)

12. T. Kulworawanichpong, J. Mwambeleko. Sustainable Energy Technologies and Assessments 12, 53-59 (2015)

13. A. Al-Karaghouli, L.L. Kazmerski, Sol. Energy 84, 710-714 (2010)

14. R. Sen, S. C. Bhattacharyya, Renewable Energy 62, 388-398 (2014)

15. G.J. Dalton, D.A. Lockington, T.E Baldock, Renew. Ener. 34, 1134-1144 (2009)

16. https://www.dji.com/matrice-200-series (access 26.04.2018)

17. http://photovoltaic-software.com/pvgis.php (access 26.04.2018)

18. H. Häberlin, Photovoltaics System Design and Practice. (John Wiley \& Sons, Ltd, 2012)

19. S. Gulkowski, Task Quarterly 19, 25-34 (2015)

20. A. Zdyb, E. Krawczak, The influence of external conditions on the photovoltaic modules performance. In Environmental Engineering V. CRC Press - Taylor \& Francis Group, Boca Raton, 261-266 (2017)

21. S. Gulkowski, J.M. Olchowik. Annual Set the Environment Protection 15, 436-447 (2013)

22. J. M. Olchowik, S. Gulkowski, K. Cieslak, J. Banas, I. Jozwik, D. Szymczuk, K. Zabielski, J. Mucha, M. Zdrojewska, J. Adamczyk, R. Tomaszewski, Mater. SciPoland 24, 1127-1132 (2006) 